\title{
Experimentation with human subjects: a critique of the views of Hans Jonas
}

\author{
Arthur Schafer Department of Philosophy, University of Manitoba
}

\section{Author's abstract}

The ethics of experimentation on human subjects has become the subject of much debate among medical scientists and philosophers. Ethical problems and conflicts of interest become especially serious when research subjects are recruited from the class of patients. Are patients who are ill and suffering in a position to give voluntary and informed consent? Are there inevitable conflicts of interest and moral obligation when a personal physician recruits his own patients for an experiment designed partly to advance scientific knowledge and only partly as therapy for those patients? The views of the eminent American ethicist Hans Fonas on these issues are briefly summarised and criticised, and some moral guidelines are then proposed to regulate experimentation on human subjects.

\section{Introduction}

The enormous recent increase in bio-medical research (1) has been accompanied by a correspondingly great increase in the literature concerned with the ethics of experimentation on human subjects. Perhaps the most influential and certainly the most frequently cited and reprinted of scholarly publications on this topic has been Hans Jonas's 1969 article, 'Philosophical Reflections on Experimenting with Human Subjects' (2). The near-classic status of this article and the extensive influence of Jonas's views - an influence encompassing both the scientific and philosophical research communities - render his article a suitable candidate for reconsideration and re-evaluation. I shall attempt, in this discussion, to show that Jonas's article, despite a number of important confusions and inconsistencies, remains a source of valuable insight into some of the dilemmas posed by medical experimentation with human subjects.

Does medical research violate 'The sanctity of human life' principle?

Jonas is a leading advocate of the principle that:

\section{Key words}

Medical experimentation; ethics; human subjects; patients; Hans Jonas. averting a disaster always carries greater weight than promoting a good. Extraordinary danger excuses extraordinary means. This covers human experimentation, which we would like to count, as far as possible, among the extraordinary rather than the ordinary means of serving the common good under public auspices (3).

According to this principle, one ought to assign a much higher priority to the value of minimising the risk of harm to research subjects than one does to the value of advancing scientific knowledge.

Jonas recognises that medical experimentation is necessary for the advance of scientific knowledge, and he recognises that the advance of scientific knowledge is necessary for the promotion of public health. He accepts that public health is a good, even a 'superlative good'. But he insists that the submission of human subjects to research which is hazardous should not be sought or accepted unless the community is faced with the sort of 'clear and present danger' which a raging epidemic poses.

Since virtually every medical procedure involves some element of risk (for example, even the taking of a blood sample carries a slight risk of infection), it may not often be morally proper to ask individuals to volunteer for biomedical experimentation. By itself, the social misfortune of those potential victims of disease whose suffering could be avoided by continuing medical experimentation does not provide a sufficient warrant for imposing risks on human subjects. The essentially melioristic goals of medical research must be subordinated to the sacrosanctity of the individual (research subject). Only a 'transcendent social sanction' can justify human experimentation. Mere benefit, however great, is not enough. On this view, even when the potential benefits from research would accrue to a large number of present and future sufferers, the principle of the individual's dignity remains inviolable.

As this summary of the first part of Jonas's argument brings out, the acceptance of Jonas's position would require the virtual cessation of medical research on human beings. 


\section{Public good and individual sacrifice}

Jonas believes that to ask volunteers for an experiment to accept foreseeable risks or burdens is a request which goes beyond, or runs counter to, what is fair to ask of the individual as a sacrifice for the common good. He concedes (insists even) that society needs to be able to call upon personal idealism in emergency situations. But the improvement of society by means of medical research is not a sufficiently critical goal. Where the very existence of society is not at stake, it would undermine the moral basis of society to demand or even to request such sacrifices.

One of the basic assumptions of Jonas's argument is that society has no right to exact from its members significant personal sacrifice for the public good. This assumption is questionable, and would be rejected by many people. It is now widely, though not universally, accepted that we have an obligation as a society to provide adequate medical care for everyone. This obligation would seem to entail that society promote the development of effective treatments. To forego medical experimentation would be to deprive ourselves of the benefits of new remedies; and not only ourselves, but future generations as well. One might argue, against Jonas, that there is a significant ethical cost attached to not doing research. Dr George James makes just this point.

In the discussion of ethical considerations relating to clinical research, the rights of the unborn generations to benefit from the fruits of research must also be weighed. It can be debated that no man today has the free and moral right to condemn his grandchildren to the same perils of disease to which he is exposed by virtue of the present lack of effective scientific information, and his failure to participate in a search for it (4).

Without extensive scientific research, employing human volunteers as subjects, we not only forego the opportunity to acquire new and more effective treatments for ourselves and for future generations, but we risk injuring ourselves with insufficiently tested remedies and procedures, old and new. To cite but one possible illustrative example from a plethora: a recent study reports that more than 150,000 children in the United States are being administered stimulant drugs as a treatment for behavioural or learning problems. Yet little is known regarding the long-term effects of such drug use (5). Given the fact of scarce medical resources, the issue of cost-effectiveness carries with it a moral dimension which, when combined with the issue of protecting public safety, tends to add further support to the conclusion that we would be ethically remiss if we were to abstain from research which is likely to yield beneficial knowledge.

Jonas contends, per contra, that self-sacrifice, in nonemergency situations, is supererogatory; and that 'our descendants have the right to be left an unplundered planet; they do not have a right to new miracle cures' (6). Unfortunately, although Jonas employs this claim as a foundation-stone of his argument, he does not defend it; nor does he indicate how he would attempt to persuade those who find his basic assumption implausible.

\section{The 'conscripting' of volunteers}

Suppose, however, that one were to concede to Jonas that we have no over-riding obligation either to present social welfare or to future generations, no obligation which could justify society in demanding of its members such personal sacrifices. Having made this concession, one might still question why it would be wrong for society to accept the willing sacrifice of volunteers. Here Jonas's position becomes rather equivocal. On the one hand, he declares that 'the mere issuing of the appeal, the calling for volunteers, with the moral and social pressures it inevitably generates, amounts even under the most meticulous rules of consent, to a sort of conscription' (7). However, this seemingly firm position undergoes several rapid qualifications and modifications, so that within a few pages, the initial blanket prohibition against medical research (in non-emergency situations) has been replaced with the conclusion that 'when the research objective is worthy enough' it is 'defensible and right' to accept certain sorts of volunteers. It will be instructive to trace the evolution of Jonas's argument as it moves from a strict to a more permissive stance.

\section{Auto-experimentation}

The first modification occurs when Jonas suggests that the moral problems posed by consent which is not truly free because it is 'conscripted' by social pressure can be circumvented. If the appeal for volunteers is addressed to the physician-researcher himself/herself, and to the scientific confraternity at large, then 'almost all of the associated legal, ethical and metaphysical problems vanish' (8). The moral advantages of such autoexperimentation are many; for when the scientific community engages in self-recruitment there will be a maximum of identification, understanding, and spontaneity.

Unfortunately, despite its theoretical moral advantages, auto-experimentation has a serious practical disadvantage. To have a reasonable chance of success in the fight against disease, medical experimentation requires a large number of research subjects (a statistically significant sample), and for many purposes these recruits must have special characteristics; for example they may have to be current sufferers from the disease under investigation.

At this point one could simply decide that the needs of medical experimentation must be subordinated to the requirements of morality. This is the conclusion one would expect Jonas to adopt, given his initial value position. Instead, he introduces further substantial modifications. 


\section{The vulnerability of patients}

Jonas is deeply troubled by the vulnerability of patients, especially sick and dying patients, to exploitation: 'the afflicted should not be called upon to bear additional burden and risk, . . . they are society's special trust and the physician's particular trust - these are elementary responses of our moral sense' (9).

But once again his position bends and his resistance to medical experimentation weakens when he confronts the hard reality that totally to disallow experimentation on sick patients would undermine the main purpose of medical research - the conquest of disease. This objective, which he had previously labelled (pejoratively) as merely 'melioristic', is now judged adequate to justify at least some experimentation on patients.

Jonas acknowledges that the moral quandary involved with using patients as research subjects is especially painful because:

all the factors that make the patient, as a category, particularly accessible and welcome for experimentation at the same time compromise the quality of the responding affirmation that must morally redeem the making use of them (10).

The patient is typically in a weakened physical state, often emotionally upset, and is likely to feel dependent upon and submissive towards those who are charged with his care and treatment. As Anna Freud notes, 'the patient is in a state of submission, admiration, obedient to the doctor' (11). This submissive deference can be easily exploited (consciously or unconsciously) by physicians engaged in scientific research who solicit their patients to participate in a research programme. Since the role of personal physician diverges significantly from that of scientific investigator - although the same person may take both roles - it seems exploitative to use the trust accumulated in the physician's traditional role as helper and healer for purposes related to his new role as scientist. The problem becomes more difficult still when the patient is gravely ill and/or institutionalised. It seems unreasonable to expect that a patient who is suffering from great pain, discomfort, emotional fatigue or distress, will be able to attend to the subtleties of a complex research project, much less rationally assess potential risks and benefits. Although there may be no question of force, fraud, or deceit, the circumstances surrounding serious illness may be thought to constitute a kind of duress. Illness frequently makes a patient more-than-normally dependent upon and eager to please his doctor. When the sick patient is also hospitalised, the dangers of subtle coercion are enhanced by the intimidation that many people feel in the hospital setting.

Jonas is fully aware of these dangers. Nevertheless, despite his awareness and concern, Jonas is forced, albeit reluctantly, to concede that if medical progress is to occur at all 'not even the superlative privilege of the suffering and the sick can be kept wholly intact from the intrusion of its needs' (10). Thus, notwithstanding his initial strictures, which seem to assign a lower priority to medical research than to the preservation of personal inviolability, Jonas at this point insists only that the duty of fidelity which the physician owes to his patient is heightened for the physician-researcher. The latter bears the onus of limiting his undue power, minimising persuasion, and guaranteeing that the research objectives are truly defensible.

\section{The principle of identification}

By the end of his paper, the principle of 'identification' provides the only absolute and unequivocal limitation to medical experimentation. No experiments on patients are permissible which are unrelated to their disease. The dignity of the patient-subject can be preserved only if it is his own kind of suffering and disease which he is helping to alleviate in others, so Jonas claims. This principle guarantees to the patient some measure of identification with the cause of scientific research.

It must be noted, however, that phrases such as 'related to his disease' are sufficiently vague that a discretionary judgment is unavoidable. Someone must decide whether the required degree of 'relatedness' is present. The phrase 'his own kind of suffering and disease' also admits of differing possible interpretations. One can adopt a more or less permissive classification system: for example, Jonas's principle provides us with no real guidance when we have to decide whether the suffering of a patient with lung cancer is or is not of 'the same kind' as the suffering of a patient with breast cancer, or the person who has suffered a stroke. This vagueness attaching to Jonas's principle renders it rather more equivocal than he appears to realise.

\section{Conclusions: some ethical guidelines for the future}

Having spent some little space tracing the threads of Jonas's argument and pointing out difficulties, inconsistencies and areas of vagueness, I would not wish to conclude the evaluation without insisting that, whatever the weaknesses of his argument, there is much to be learned from it. In particular, Jonas offers us an important reminder of the danger that the utilitarian principle of maximising overall social good could lead us to permit experiments which violate other important moral values, such as the principles of individual dignity and distributive justice. Jonas reminds us forcefully that medical ethics is not solely an ethics of maximising benefits and minimising harms. The ideals of distributive justice and individual dignity should act as a 'brake' or check against the sort of crass benefit-producing ethic which would classify some individuals as fit to be conscripted forcibly for some social end because they are burdensome and therefore socially 'expendable'. 
It may be that the benefits of continuing to support a vast research effort are so great that society will feel that it has 'no choice' but to accede to the growing tendency to use patients as subjects. After all, human dignity can be severely undermined by serious illness as well as by the human experimentation designed to eliminate such illness. There is an ethical cost attaching to not doing such research as well as to proceeding with it. If one is faced with a choice between protecting personal dignity by imposing a total ban on human experimentation or, alternatively, protecting the dignity of potential beneficiaries of research (present and future generations) by permitting such experimentation to proceed, it is defensible to be influenced by the numbers of people affected and the degree of benefit and harm to each. As Lasagna comments, 'there is nothing intrinsically more noble about a concern for the individual than a desire to aid the many; in fact, it might be argued that the opposite underlies the democratic process or the social contract in general' (12).

After eschewing the utilitarian approach to such ethical dilemmas, Jonas seems finally to adopt it himself. But he does so with great reluctance, cautiously, and with numerous qualifications and reservations. From these we can learn much.

The absolutist, either/or, tendency of Jonas's argument is not, I think, an approach which it would be realistic or ethically desirable for society to adopt in setting policy for human experimentation. More promising would be a general principle according to which the greater the risk of harm to subjects of experimentation and the greater the seriousness of the harm risked, the higher should be the level of competence required of subjects for valid consent. On this proposal, the greater the obstacles to voluntary consent inherent in the potential subject's condition (pain, distress, acute depression, etc) or his/her circumstances (hospitalised, dependent, etc) the less will be the ethically permissible level of risk imposed by the experiment. Particularly hazardous experiments should gather their subjects from the most free and best informed members of society. Experiments which pose little or no risk to their subjects might be allowed to proceed even if the quality of consent given by the subject is less than ideal.
It may be that the best we can do, when dealing with $\stackrel{\mathbb{Q}}{\alpha}$ prospective research subjects whose conditions or $m$ circumstances raise doubts as to their autonomy is to proceed, if at all, only with great caution, and only ? where there is a demonstrable compelling need for the proposed research to use this subject pool. Where there exists serious reason to doubt the quality of the potential subject's consent, no experiment should be permitted in which there is a significant risk of serious harm; and if an alternative (and ethically less questionable) pool of subjects is available, it should be कै mandatory that it be chosen instead. Jonas's suggestion of a 'descending order of permissibility' provides us with a useful guideline (13). Those who are least able to give voluntary and informed consent should be the last chosen as subjects for hazardous research.

\section{References and notes}

(1) By the 1970 s, federal funding for bio-medical research in North America amounted to several billion dollars $\sigma$ annually, taking second place only to weapons research. 음 To illustrate the rapidity of this expansion: in the 20year period, 1945-1965, the annual expenditure for medical research (mostly involving human subjects) by the United States National Institutes of Health increased 624-fold. See: Beecher H. Ethics and clinical research. New England journal of medicine 1966; 274: 1354-1360.

(2) Jonas H. Philosophical reflections on experimenting with human subjects. Daedalus, the Journal of the American Academy of Arts and Sciences 1969; 98: $219-247$.

(3) See reference (2): 229.

(4) Cited by: Marston R Q. Medical science, the clinical trial and society. In: Beauchamp $T \mathrm{~L}$, Walters $\mathrm{L}$, eds. Contemporary issues in bioethics. California: Dickinson, 1978: 409.

(5) Sroufe J A, Stewart M A. Treating children with stimulant drugs. New England joumal of medicine 1973; 289: 407

(6) See reference (2): 230.

(7) See reference (2): 233.

(8) See reference (2): 234.

(9) See reference (2): 238.

(10) See reference (2): 239.

(11) Quoted by Gray B. Human subjects in medical experimentation. New York: Wiley 1975: 88.

(12) Lasagna L. Special subjects in human experimentation. I In: Freund $\mathrm{P} A$, ed. Experimentation with human subjects. New York: George Brazilles, 1969: 274.

(13) See reference (2): 236-237. 